\title{
Solid-phase extractions in flow analysis
}

\author{
FÁBIO R.P. ROCHA ${ }^{1}$, ALEX D. BATISTA ${ }^{2}$, WANESSA R. MELCHERT ${ }^{3}$ and ELIAS A.G. ZAGATTO ${ }^{1}$ \\ ${ }^{1}$ Centro de Energia Nuclear na Agricultura, Universidade de São Paulo, \\ Avenida Centenário, 303, 13400-970 Piracicaba, SP, Brazil \\ ${ }^{2}$ Instituto de Química, Universidade Federal de Uberlândia, \\ Av. João Naves de Ávila, 2121, 38408-100 Uberlândia, MG, Brazil \\ ${ }^{3}$ Escola Superior de Agricultura "Luiz de Queiroz", Universidade de São Paulo, \\ Caixa Postal 9, 13418-970 Piracicaba, SP, Brazil
}

Manuscript received on July 5, 2017; accepted for publication on October 9, 2017.

\begin{abstract}
Coupling solid-phase extraction (SPE) to flow systems has promoted a synergistic development. Whereas SPE mechanization leads to improved precision and higher sample throughput, as well as diminishes systematic errors and contamination risks, analyte concentration and separation from the sample matrix provides a remarkable impact on detectability and selectivity in flow analysis. Historical aspects, main cornerstones, tips for system design, and recent applications are critically reviewed, in the context of analyte(s) separation/concentration, sample clean-up, and release of sorbed chemical species involving both packed (e.g. mini-columns, cartridges, and disks) or fluidized (e.g. beads and magnetic materials) particles. Novel (bio)sorbents, selective synthetic materials, and stationary phases for low-pressure chromatography are also discussed. Moreover, the feasibility of SPE for sample treatment before chromatographic separation, as well as the exploitation of direct measurements on the solid phase (optosensing) are emphasized.
\end{abstract}

Key words: beads, flow analysis, in-line analyte concentration, in-line sample treatment, sample clean-up, solid-phase extraction.

\section{INTRODUCTION AND HISTORICAL ASPECTS}

Solid phase extraction (SPE) is a widely used strategy for sample clean-up and for enhancement of analytical sensitivity, selectivity or both (Buszewski and Szultka 2012). In general, SPE involves transference of the analyte(s) from a liquid sample to a solid sorbent, usually followed by elution. A typical cycle for analyte separation/concentration

Correspondence to: Elias Ayres Guidetti Zagatto

E-mail: ezagatto@cena.usp.br

* Contribution to the centenary of the Brazilian Academy of Sciences. comprises: (i) Conditioning: a suitable solvent or solution passes through the sorbent to activate its functional groups, and the excess is removed; (ii) Loading: a defined sample volume is placed in contact with the sorbent and either the analyte(s) or potentially interfering species are retained; (iii) Washing: a rinsing solution removes the residual sample from the sorbent void volume; (iv) Elution: the eluent(s) passes through the sorbent for releasing the analyte(s). Equilibrium conditions are generally required when the process is carried out batchwise and, consequently, SPE may become time-consuming. 
In practice, a simplified SPE strategy is preferred, thus the possibility of performing two steps in conjunct (e.g. loading and washing) is highly attractive. This aspect is generally attained when SPE is implemented in a flow analyzer. In fact, loading occurs during the transient interaction of the sample zone with the sorbent, whereas washing takes place during passage of the carrier stream through the sorbent.

In segmented flow analysis (Skeggs 1957), few applications exploiting SPE have been reported for analyte separation/concentration, although minicolumns and cartridges with suitable adsorbents were already commercially available in 1973 (van Gemert 1973). Anyway, some applications involving sample clean-up were proposed, and the landmark article focused on sulfate determination in waters (Gales et al. 1968). The unsegmented sample stream was pumped through a mini-column filled with a Dowex-50 W-X8 cation-exchange resin in which the potential interfering ions were retained; the depleted sample merged with a segmented barium chloranilate stream yielding the slightly soluble barium sulfate, and releasing the colored chloranilic acid; the handled sample was then in-line filtered, monitored at $520 \mathrm{~nm}$, and discarded.

The scarce number of SPE applications in segmented-flow analysis is due to the drawbacks of introducing air-bubbles in the sorbent mini-column. This limitation can be overcome by applying a novel extraction principle relying on functionalized magnetic beads (Rendl et al. 2014, Schönberg et al. 2015). The beads are added to every aqueous sample segments, yielding highly reproductive suspensions. After sorption of the species of interest, the beads are retained by a magnet and further exposed to an eluent under unsegmented flow conditions.

Unlike segmented flow analysis, exploitation of SPE in unsegmented flow analyzers has been remarkable. In fact, the implementation of SPE in flow injection analysis (Ruzicka and Hansen 1975, Stewart et al. 1976) and related techniques is worthy for the development of environmental friendly analytical procedures compatible with a large number of samples. Additionally to analyte separation and concentration, monitoring of desorbed chemical species has been proposed for e.g. bio-accessibility assays (Vida et al. 2016), estimative of nutrient release from soils (Machado et al. 2017), and speciation analysis (Pons et al. 2005).

The advantages of in-line SPE in unsegmented flow analysis were already noted during the early developments of flow injection analysis (Hansen and Ruzicka 1983). In this context, the pioneer work dealt with ammonium determination in natural waters (Bergamin-Filho et al. 1980). An Amberlite IR-120 resin mini-column replaced the sampling loop of a sliding bar injector. In the loading position, the sample was aspirated through the mini-column, where ammonium was retained, and the sample excess was discarded. Switching the injector to the eluting position intercalated the mini-column into the eluent stream, and the analyte zone was directed towards detection. Thereafter, the zone interacted with the Nessler reagent added by confluence (Bergamin-Filho et al. 1978), and the reaction product was monitored by both radiation absorption and light scattering at $410 \mathrm{~nm}$. Regarding selectivity improvement, interferences of phosphate and sulfate on the determination of calcium by flame atomic absorption spectrometry were circumvented by removal of these anions by in-line ion-exchange (Kamson and Townshend 1983).

Different procedures for in-line SPE involving packed or fluidized sorbents, realtime decisions based on concentration-oriented feedback mechanisms, multi-channel manifolds, and flow reversals, have been implemented in unsegmented flow analyzers. As the involved steps are mechanically accomplished, analytical 
precision tends to be enhanced, and human errors are minimized. Risks to the analyst due to exposure to hazardous chemicals are reduced because the entire process takes place inside a closed system. Moreover, sample contamination and/or analyte losses are minimized. The amounts of samples, reagents, and solvents typically diminish, and further reduction can be attained through system miniaturization or some special flow modalities. The above features are in adherence to the concept of Green Analytical Chemistry (Gałuszka et al. 2013).

In flow-based SPE, the time intervals available for the involved physicochemical processes are highly reproducible, allowing the development of analytical methods where equilibrium conditions are not attained. Consequently, non-exhaustive extractions can be precisely carried out, allowing the advantageous mechanization of solid-phase micro-extraction (SPME) in flow analysis (Belardi and Pawliszyn 1989, Arthur and Pawliszyn 1990).

Most applications of SPE in flow analysis aimed at single analyte determinations or sample clean-up. Anyhow, the feasibility of simultaneous determinations relying on sequential elutions was demonstrated in some applications involving e.g. successive injections of different eluents (Burguera et al. 1981), concentration gradients (Maniasso et al. 1996) or monolithic columns (Fernández et al. 2012).

In this review, the main aspects inherent to SPE in unsegmented flow analysis are discussed, with emphasis to manifold design, potentialities, limitations, and applications.

\section{MANIFOLD DESIGN}

SPE can be implemented in different modalities of unsegmented flow analyzers and the manifold is usually designed either with a packed minicolumn or a SPE cartridge. Three basic system configurations (Fig. 1) have been usually exploited (Zagatto et al. 1993).

In the original implementation of SPE in unsegmented flow analysis, the mini-column with the solid sorbent (MC) was placed in the loop of an injector-commuter (Figure 1a, MC in position $1)$. The main advantage of this configuration is that the mini-column is displaced between two rather different streams, one accountable for the conditioning and loading steps, and the other, for the elution and washing. The depleted sample is discarded without passing through the detection unit. Also, more effective elution under countercurrent flow conditions is straightforwardly accomplished. The sample volume is generally defined by the sample aspiration rate and sampling time. With zone sampling (Reis et al. 1981), the sample volume is defined by the sampling loop: the sample zone established into the first carrier stream is directed towards the mini-column, and switching the injector intercalates the sorbent into the eluent stream. The mini-column is then washed after every sorption step.

Another basic configuration (Figure 1a, MC in position 2) involves the placement of the minicolumn between the injector and the detector (Burguera et al. 1981). Sample and eluent solutions are sequentially inserted into the carrier stream, and the successive zones flow through the minicolumn towards detection. The manifold is simple, but the pronounced concentration gradients can hinder detection. Consequently, the Schlieren effect may impair the detection limit (LOD) in spectrophotometric and luminometric methods (Dias et al. 2006). Moreover, elution may be only partial because of the limited eluent volume. This basic configuration has been preferred in sequential injection analysis (SIA), as shown in Figure 1b (Miró et al. 2000, Economou 2005), because solutions handling is improved by the multiport valve and feasibility of flow programming. In SIA, the solutions are sequentially aspirated towards 
a

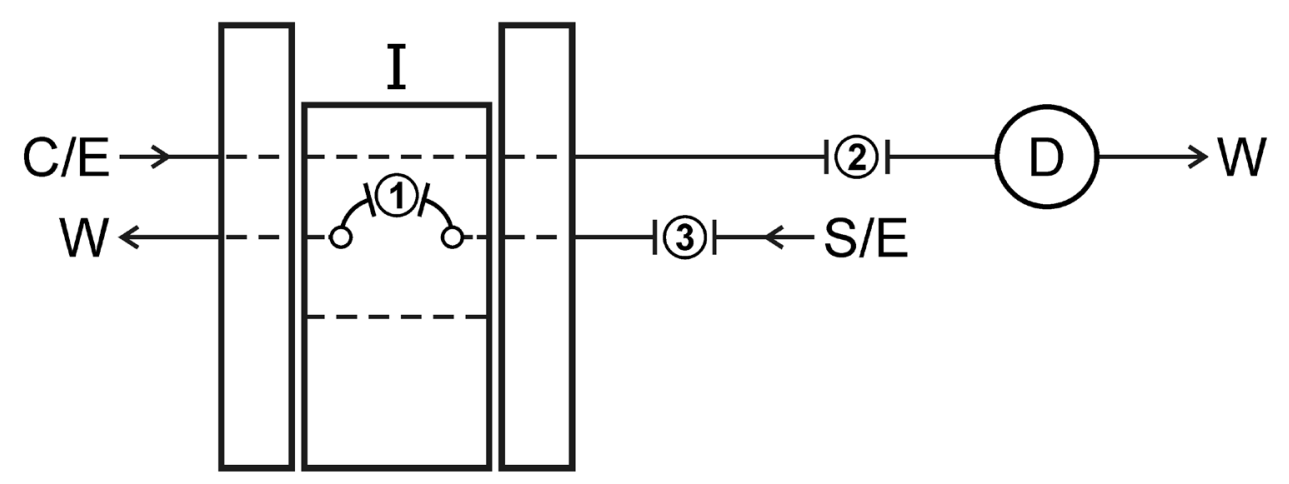

b

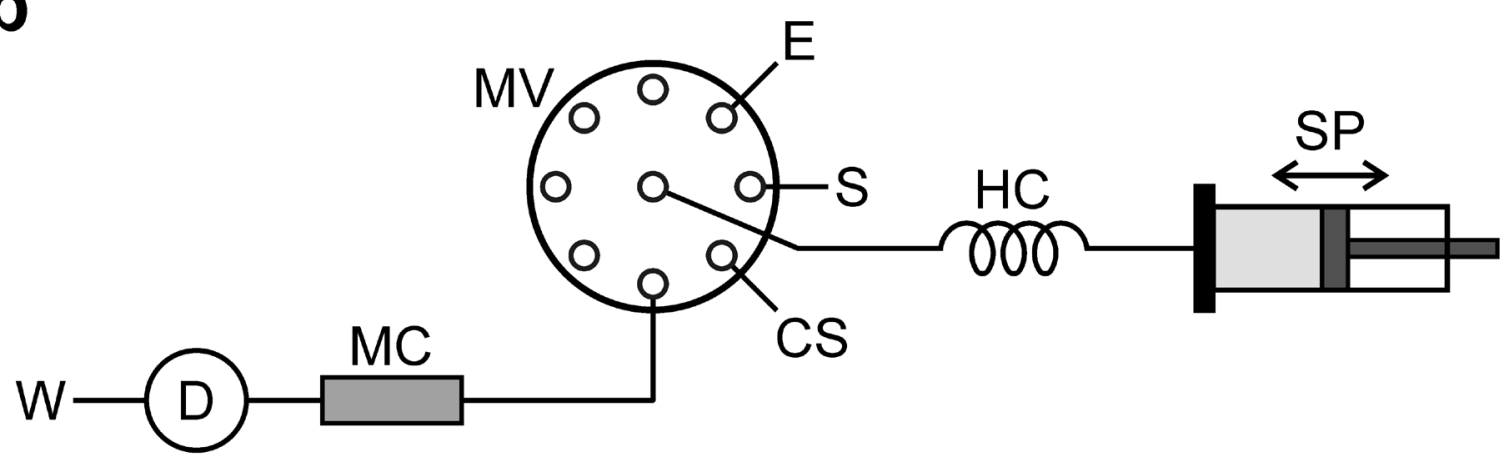

C

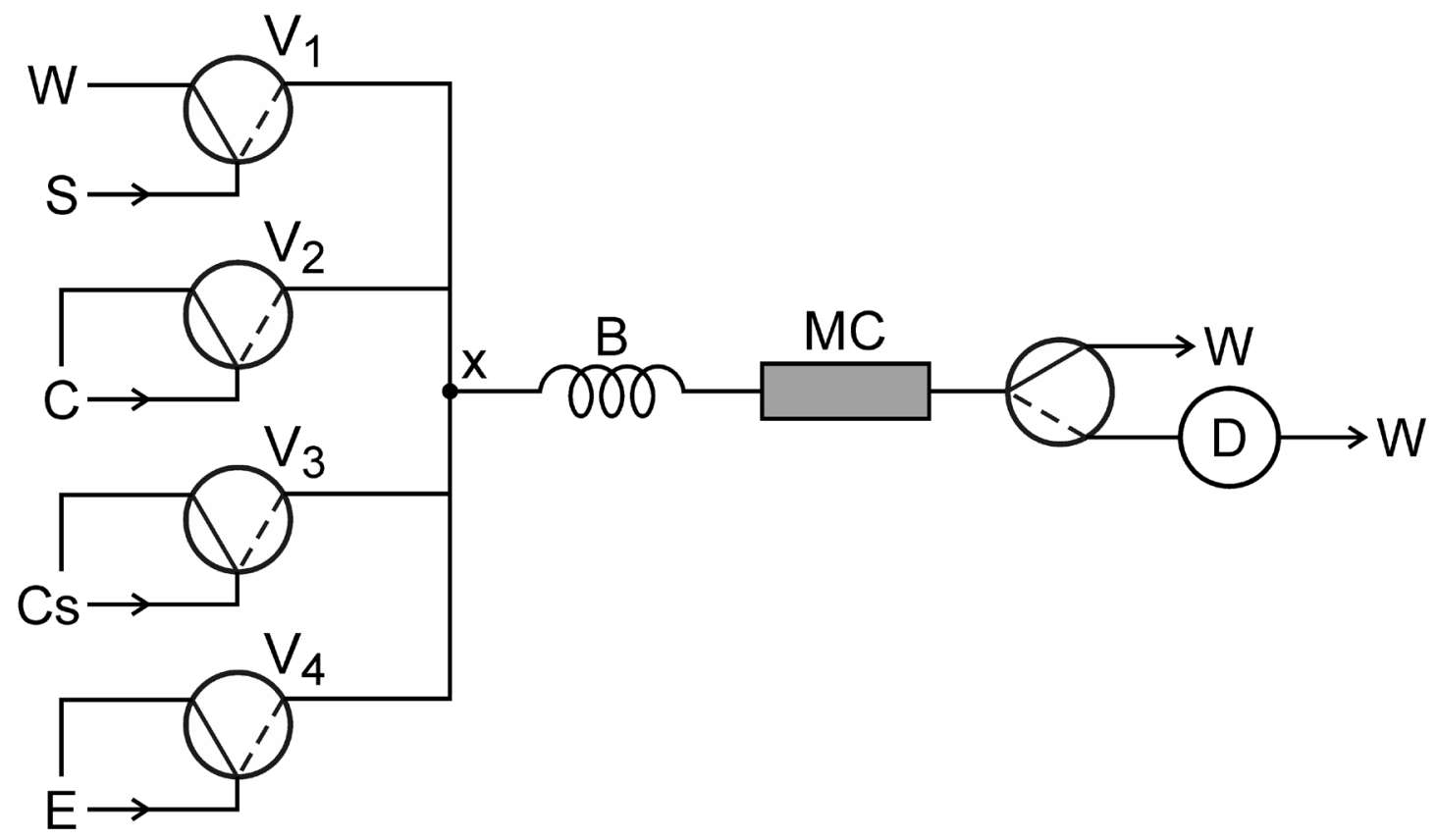

Figure 1 - Flow diagrams of analytical systems with SPE mini-columns (MC): (a) FIA with a sliding bar injector (I). MC placed in positions 1, 2 or 3; (b) SIA and (c) MCFA; S: sample; B: mixing coil; C: carrier stream; CS: conditioning solution; D: detector; E: eluent; HC: holding coil; MV: multi-position valve; SP: syringe pump; Vi: solenoid valves; x: confluence joint point; W: waste recovery vessel. 
a holding coil and then driven through the minicolumn. The main drawback refers to the mutual dispersion of the aliquots (e.g. sample and eluent; eluent and conditioning solution) at the interfaces, which can hinder the analyte sorption or elution. Some approaches to circumvent this drawback include insertion of an air plug between the carrier and eluent (Chomchoei et al. 2005) and exploitation of programmable flow to complete the sample loading before aspiration of the eluent solutions (Chisvert et al. 2002). The later demonstrates the feasibility of SIA for independent managing of sample, eluent, and conditioning solutions. Other configuration (Figure 1a, MC in position 3) relies on the mini-column placed before the injection port aiming at sample clean-up. Potential interfering species are removed, but a high adsorption efficiency of the sorbent is required. The species in the interstitial phase can also be transferred to the sample loop. Periodic elution is required to avoid sorbent overload, which depends on the sample loaded volume and concentrations of the potential interfering species.

With multicommutation (MCFA), the versatility of the above-mentioned basic configurations is improved (Rocha et al. 2002), as demonstrated by the increasing number of analytical applications. A MCFA flow system designed in the basic configuration is shown in Figure 1c. As previously mentioned in relation to SIA, the efficient solution handling permits the independent implementation of all the steps involved in SPE, i.e. sorbent conditioning, sample loading, washing to remove the interstitial solution, and elution (Gonzáles et al. 2009). MCFA also allows coupling of flowbased SPE with inherently discontinuous detection systems, such as ETAAS (Silva et al. 1998). A useful approach is coupling the mini-column at the autosampler arm. Sample and conditioning solutions are sequentially driven through the sorbent under reproducible timing and flow rates. Then, a few microliters of eluent are aspirated through the sorbent and the eluate is directly delivered into the atomizer. If necessary, further elution can be carried out before the next measurement cycle. These characteristics, mainly the improved versatility, hold also for the multi-syringe flow systems (Miró et al. 2002). Because of the capability of the syringe pump to deliver low volumes with good precision, the consumption of reagents and eluent can be minimized.

Attention should be given to the column geometry and sorbent characteristics (e.g. functional groups, particle size, and breakthrough capacity). Smaller particles are preferred because of the higher surface area, but particle size cannot be decreased at will in order to prevent a pronounced increase in backpressure. Some sorbent materials undergo volume changes due to swelling or shrinking effects. Irreversible contamination, deactivation of the surface or even loss of active sites may also occur. During long-time utilization, preferential pathways may be established inside the minicolumn, limiting the interaction of the sample with the sorbent. These aspects can be circumvented by exploiting functionalized moving beads and the number of applications of this approach has increased, especially in the context of bead injection analysis (Ruzicka and Scampavia 1999), including lab-on-valve (Boonjob 2014)), MSFIA (Pons et al. 2005), SIA (Wang and Hansen 2001, Sartini et al. 2002), magnetic beads (Ampan et al. 2002), and fluidized beds (Ribeiro et al. 2006).

Application of stir bar sorptive extraction in flow analysis was recently proposed also aiming at to maximize the sample/sorbent interaction, as well as to minimize backpressure. The sorptive bar was placed inside a chamber and submitted to magnetic stirring in a MSFIA system (Ghani et al. 2016b). Stir bar coatings were prepared from a mixture of montmorillonite and epoxy resin, in which different reagents can be physically or chemically adsorbed. Under suitable experimental conditions, analyte adsorption can be reversible, thus favouring the 
reuse of the same sorbent in several retention/ elution cycles.

Flow systems have been also exploited for analyte concentration or sample clean-up before chromatographic separation. This hyphenation synergistically enhances the advantages of each process especially in relation to complex samples, analytes at trace levels, or both, with increased sample throughput, good precision, and low reagent consumption and waste generation. Moreover, this approach significantly diminishes the operational costs in comparison to commercially available apparatus for mechanization of SPE. In this sense, MSFIA was used for sample treatment before determination of the beta-blockers atenolol and propranolol in human plasma (Brunetto et al. 2015). The pretreatment involved deproteinization by SPE with a restricted access material and chemical derivatization under microwave-assisted heating to produce volatile trimethylsilated derivatives, which were suitably separated by GC before MS detection. A sampling rate of $7 \mathrm{~h}^{-1}$ was attained by performing sample treatment and chromatographic separation simultaneously.

Miniaturization is a fertile research field in flow analysis, with clear advantages in relation to reagent and sample consumptions as well as to portability. Moreover, the large surface-tovolume ratios inherent to microchannels and the dispersion fundamentally caused by diffusion open new perspectives of applications. In this sense, exploitation of solid-phase extraction in microfluidics has been extensively investigated and the main challenges are the risks of excessive backpressure, clogging, and fluid leakage, especially because of swelling of the sorbent. This drawback has been circumvented in different ways, such as use of elastomeric substrates to build up the microfluidic devices (Magalhães and Fonseca 2017), direct preparation of monoliths by photopolymerization in microchannels (Yang et al. 2015), and exploitation of bead sorbents (Verpoorte
2003). Alternatively to the design of dedicated microfluidic devices, SPE has been successfully exploited in lab-on-valve systems (Vidigal et al. 2013). However, under a practical point of view, capability to in-field analysis is often hindered by lack of ruggedness.

\section{NON-CHROMATOGRAPHIC SEPARATIONS}

Flow-based methods have been usually focused on the selective determination of a single analyte encompassing advantages such as high sample throughput and improved precision. On the other hand, liquid chromatography usually aims at the separation of a group of analytes from each other and from the sample matrix. In this sense, these techniques are complementary and hyphenation can synergistically improve the overall performance including, for instance, in-line sample treatment (clean-up or analyte concentration) in a flow system previously to chromatographic separation (Brunetto et al. 2015, Ghani et al. 2016a). Chromatographic separations have been incorporated to flow analysis by using short (monolithic or fused-core) columns able to operate at relatively low pressures. This topic is further discussed.

In-line separations have been sometimes exploited in flow analysis for improving selectivity and/or for simultaneous determinations. The applications are distinct from typical chromatographic approaches mainly because the flow systems operate at a relatively low pressure (usually $<100 \mathrm{psi}$ ), thus requiring more porous materials and/or high particle size, in order to avoid excessive backpressures. This can critically hinder the separation efficiency, leading to significant band broadening in comparison to HPLC. This drawback may limit the applications to separation of a few species or, more usually, a single analyte from the sample matrix. Ingenious approaches have then been proposed to improve the separation capacity in flow analysis, including use of biosorbents, novel 
synthetic selective materials (e.g. molecularly imprinted polymers), as well as optosensing, which are discussed separately. Illustrative examples of non-chromatographic separations in flow analysis include: (i) separation of $\mathrm{Cd}(\mathrm{II})$ from interfering species, e.g. $\mathrm{Pb}(\mathrm{II})$ and $\mathrm{Cu}(\mathrm{II})$, by retaining the corresponding chlorocomplexes in a mini-column packed with an anion exchange resin aiming at determination in foodstuffs (Gomes-Neto et al. 1995); (ii) environmental friendly determination of nitrate in natural waters involving UV spectrophotometry after in-line analyte separation from other absorbing species, e.g. organic matter, by ion-exchange (Melchert and Rocha 2005); and (iii) exploitation of polyurethane foam without (Ferreira et al. 1999) or with (El-Shahat et al. 2010) chemical modification for separation of interfering species in nickel determination or for determination of penicillins, respectively. The latter application was based on methylene blue grafted polyurethane foam aiming at analyte concentration and separation from the sample matrix (milk or pharmaceutical formulations), whereas the former exploited the retention of metal ions, e.g. $\mathrm{Fe}(\mathrm{III}), \mathrm{Cu}(\mathrm{II}), \mathrm{Zn}(\mathrm{II})$, and $\mathrm{Co}(\mathrm{II})$, as thiocyanate complexes aiming at selective spectrophotometric determination of $\mathrm{Ni}$ in alloys and rocks.

\section{IMPROVED SAMPLING RATE AND SAMPLE UTILIZATION EFFICIENCY}

Analytical procedures involving analyte separation/ concentration are usually time-consuming, mainly because of the time spent at the loading step. Although this aspect is less critical in flowbased procedures, some approaches have been proposed for improving sample throughput without hindering the enrichment factor (EF). As the sample consumption is a limiting factor in some applications of e.g. clinical or forensic interest, the loading efficiency also needs to be maximized. These aspects can be evaluated by considering the concentration efficiency (CE) and consumptive index (CI) (Fang 1993), rather than directly from the EF values. The former refers to the EF achieved per unit of time (typically one minute), whereas CI indicates the sample volume required to increase the EF in one unit.

Both CE and CI are inherently improved when several analytes are simultaneously concentrated, a situation typically observed in flow systems involving multielemental detectors (e.g. ICPs) and/or unselective sorbents. In this situation, the experimental conditions for sample loading (e.g. sample flow rate and sorbent amount), elution, and detection are established as a compromise by considering all the involved analytes.

Some novel sorbents stand out by fast analyte sorption and low backpressure, thus resulting in relatively high $\mathrm{CE}$ values. For example, the sorbent based on a poly(vinylpyridine)-supported protoporphyrin yielded a high CE $\left(17.6 \mathrm{~min}^{-1}\right)$ by loading $18.0 \mathrm{~mL}$ of sample at a relatively high flow rate $\left(6.0 \mathrm{~mL} \mathrm{~min}^{-1}\right)$ in a flow injection analyzer (Oliveira et al. 2013). Analytes were efficiently retained and eluted, as demonstrated by the CI of $0.34 \mathrm{~mL}$. The sorbent material was successfully applied to Mn concentration before detection by FAAS aiming at analysis of natural waters, food, and sediments. It should be emphasized that the optimal flow rate at the loading step critically depends on the adsorption kinetics, thus on the physicochemical characteristics of both analyte and sorbent.

More general strategies for improving sampling rate and efficiency of sample utilization (i.e. high $\mathrm{CE}$ and $\mathrm{CI}$ ) involve modifications in the system design. In this sense, the simultaneous loading of two mini-columns followed by sequential elution exploiting intermittent pumping of the eluent was proposed (Fang et al. 1984). Even with a sample throughput of $60 \mathrm{~h}^{-1}$, the detectability achieved with FAAS was comparable to that obtained by GFAAS. The strategy was further expanded, with 
four mini-columns replacing the sample loops of a sliding bar injector for the determination of $\mathrm{Cd}$ by FAAS (Miranda et al. 1995) and the simultaneous determination of $\mathrm{Cd}, \mathrm{Ni}$, and $\mathrm{Pb}$ by ICP OES in a MCFA system comprising three mini-columns (Miranda et al. 2002). By simultaneously carrying out the loading steps, one expects that $\mathrm{CE}$ increases proportionally with the number of minicolumns, but the sample consumption (and thus CI) was not reduced. Other hindrance refers to the need for highly similar mini-columns to achieve reproducible results. In practice, the precision of results obtained in different columns is usually lower than that estimated for a single column. This drawback is not significant when mini-columns are filled with different materials for retention of different species. This approach was exploited for chemical speciation based on the retention of free metal ions in a chelating resin followed by adsorption of complexes on an anion-exchanger (Liu and Ingle 1989), and for the simultaneous inline concentration of cations and anions exploiting mini-columns placed in series, followed by elutions of the sorbed species in parallel flow channels (Rocha et al. 2004). The latter application exploited the versatility of relocating the mini-columns placed as sampling loops of a sliding-bar injector.

Expert systems are another alternative to improve the analytical productivity in procedures involving SPE, as demonstrated in the sequential spectrophotometric determination of anions in natural waters (Rocha et al. 2001). Chloride, nitrate, nitrite, and phosphate were determined by inserting selective reagents in a continuously flowing sample, which also acted as the carrier of the sample zone. In this way, during the measurement of the transient signals, the sample stream was bypassed through a mini-column filled with an anion exchanger for in-line concentration of the analytes. According to a feedback-oriented mechanism relying on the measured transient signals, a species in concentration lower than LOD by the direct measurement could be measured with improved sensitivity after elution of the analytes previously retained in the mini-column. With this strategy, a 180 -s loading time was implemented even with a $50 \mathrm{~h}^{-1}$ sampling rate. Further, feedback mechanisms were exploited for real time decision on the need for analyte preconcentration, as well as for performing chemical speciation, as demonstrated in iron determination (Pons et al. 2004). These expert systems exploited the advantages of MCFA for independent solution handling.

\section{BEAD INJECTION}

Bead injection analysis involves management of a suspension of beads into a flow system (Fig. 2a). A chromogenic reagent is previously adsorbed on the beads and the sorbent is retained in a specific cell (called a jet-ring cell) where separation, reaction, and detection are in-line carried out. After measurement, the beads are discarded or renewed (Rama et al. 2003).

Poly(styrene-divinylbenzene), agarose or poly(vinylpirrolidone) are commonly used as beads, and uniform spherical shape and size is preferred (Miró et al. 2008). Otherwise, a re-suspension stage is required to promote fluidization, which significantly improves precision in comparison to direct aspiration of suspensions of non-uniform beads, $1.6<$ r.s.d. $<13.8$ and $3.8<$ r.s.d. $<67.6 \%$, respectively (Oliveira et al. 2011).

Bead injection allows renewing the solid phase before each loading step, thus avoiding problems of contamination, preferential pathways, and mainly irreversible analyte retention. On the other hand, this implies in higher sorbent consumption. The approach can be suitably combined with optosensing (as further discussed in this review) aiming at improved sensitivity and analyte accumulation in the beads typically yields low LODs (Miró et al. 2008). 
(a)

(b)
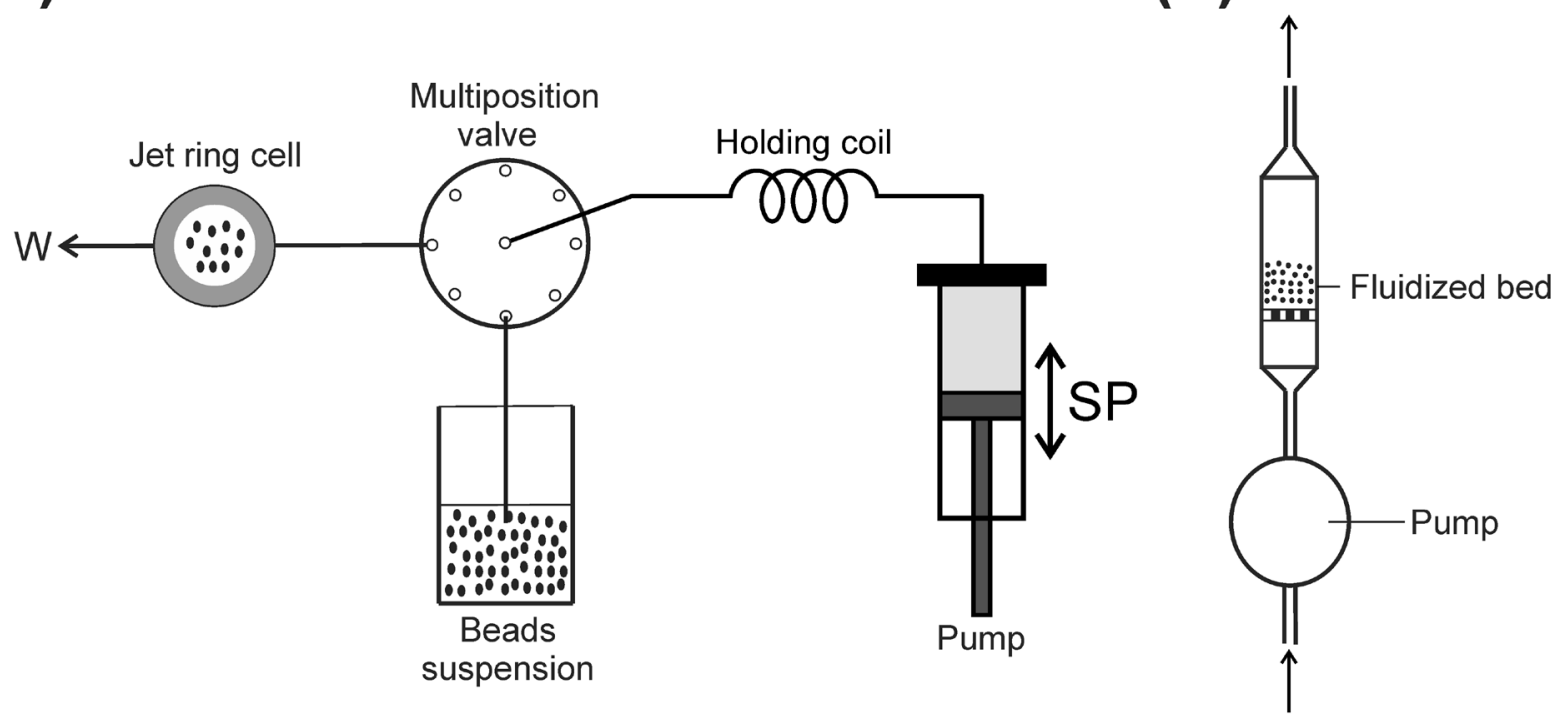

(c)

(d)
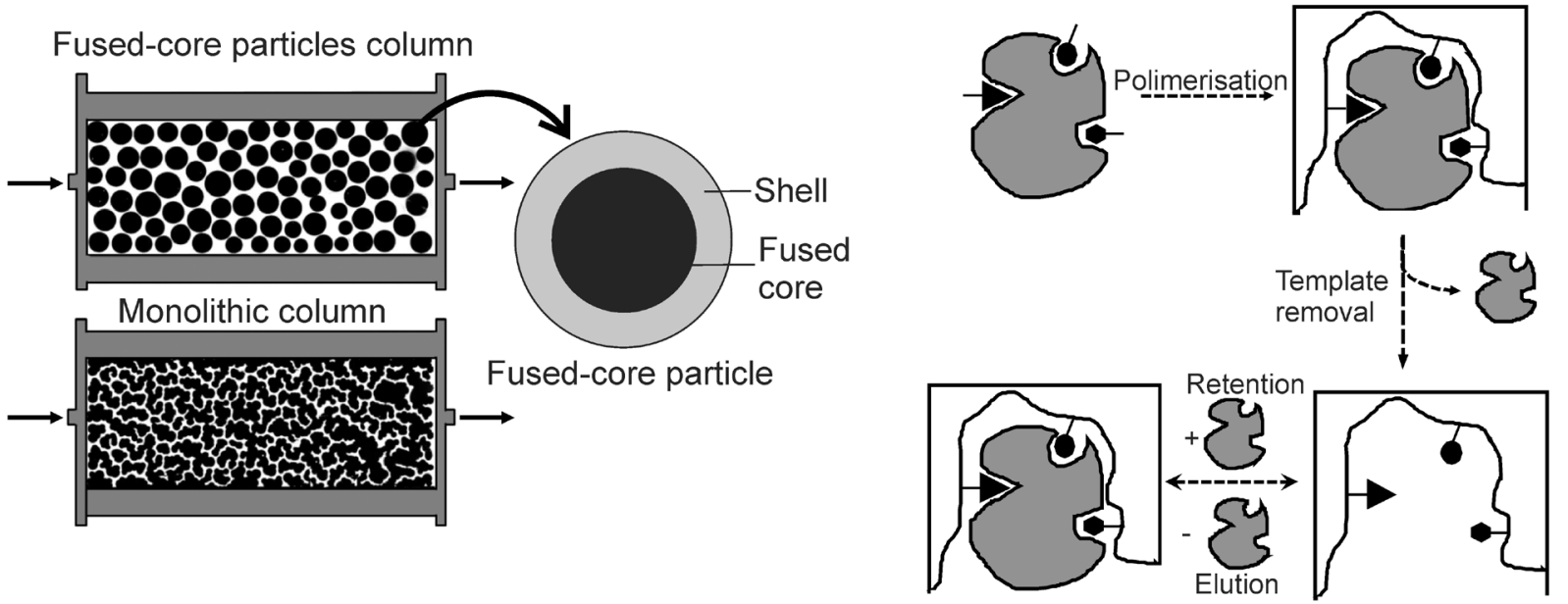

Figure 2 - Some approaches for flow-based SPE: (a) bead injection; (b) fluidized beads; (c) low-pressure chromatography, and (d) molecularly imprinted polymers.

Spectrophotometry, fluorimetry or chemiluminescence have been generally used as detection techniques. Coupling with ETAAS is possible by directly introducing polymeric organic beads into the graphite furnace (Miró et al. 2008). Moreover, bead injection has been coupled with amperometric detection and electrochemical jet ring sensor based on enzyme immobilized on the beads surface (Silvestre et al. 2011).

Bead injection has been usually implemented in SIA because of the versatility provided by the multi-position valve and possibility of flow reversal, which is attractive for effective handling of the bead suspensions. The pioneer work involved 
a specially designed flow cell, consisting in a tube perpendicular to a flat surface with a narrow circular gap from where the liquid could escape radially. A uniform perfusion and the simultaneous monitoring of the entire bead layer were then accomplished (Ruzicka and Scampavia 1999).

Feasibility of renewal of the ion exchange beads at each measurement cycle in ETAAS was demonstrated by exploiting a six-port selection valve with micro-channels (Wang and Hansen 2001). Tubes with a 10-fold smaller diameter than the beads were introduced within two microchannels to retain the sorbent. After sample and bead insertion into the mini-column, the analyte was eluted from the beads and the eluate was directed towards the atomizer under segmented flow conditions. The strategy improved precision and selectivity for Ni determination in environmental and biological samples.

Ten $\beta$-blockers were determined in environmental samples by coupling a SIA-bead injection analyzer with liquid chromatographyelectrospray ionization tandem mass spectrometry (Boonjob et al. 2015). The procedure allowed in-line sample clean-up with bead suspensions, analyte separation/concentration, and detection; EFs within $62-74$ and recoveries from 74 to $86 \%$ were estimated.

A lab-on-valve system was used for spectrophotometric determination of $\mathrm{Fe}(\mathrm{II})$ in acidified seawater samples by 1,10-phenanthroline method, by exploiting a cellulose-based chelating sorbent beads containing 8-hydroxyquinoline (Horstkotte et al. 2016). Before aspiration, air inlet and vortexing were accomplished for resuspending the beads. System stability was evaluated by repeated analysis over $15 \mathrm{~h}$ without significant variations in analytical signals; the coefficient of variation was estimated at $1.6 \%$ after 61 determinations.

\section{FLUIDIZED BEDS}

Fluidized beds refer to conversion of a solid granular material from a static to a dynamic fluidlike state, establishing a chaotic but reproducible $4 \pi$ geometry, aiming at improving the solid/liquid interaction. In flow analysis, fluidization can be attained by placing the solid material inside a vertical tubular chamber and letting a pulsed liquid stream to pass through it (Ribeiro et al. 2006), as show in Fig. 2b. Otherwise, mechanical stirring, air inlet, sonication or magnetic beads can be exploited. With fluidized beds, limitations due to the establishment of preferential pathways, high backpressure, bead expansion or compression, and poor accessibility to active sites are minimized. Fluidized beds have been exploited in e.g. analytical methods involving in-line SPE (Vakh et al. 2017), relatively slow chemical reactions, and analyte sorption/leaching (Rosende et al. 2010).

The innovation has proved to be also useful for dynamic extraction in metal bioaccessibility assays, evaluation of soil capacity, chemiluminometric determinations, and analytical methods relying on immobilized reagents. The multi-pumping flow system (MPFS) designed for the dynamical evaluation of the soil capacity to adsorb phosphate (Machado et al. 2017) can be mentioned as an example. A phosphate standard solution passed through a fluidized bed column with $50 \mathrm{mg}$ of soil (particles $<0.15 \mathrm{~mm}$ ), where the analyte was adsorbed. The remaining phosphate was then in-line quantified by the spectrophotometric molybdenum blue method. Excellent figures of merit were attained, in addition to 40, 100, and 180fold reductions in waste generation, soil amount, and analysis time in comparison to the reference procedure. Other relevant aspect is that soil nonhomogeneity becomes less critical, corroborating previous observations (Rosende et al. 2010).

A fluidized-bed reactor was used in a MPFS for the chemiluminometric determination of uric 
acid in saliva (Vakh et al. 2017). It consisted of an anion-exchanger placed into a cylindricallyshaped glass tube with inlets at the bottom and top. The pulsed flow delivered by a solenoid pump fluidized the resin and separated the analyte from the sample matrix. The anion-exchanger was used in up to 1500 sorption-desorption cycles, without increasing backpressure.

Stepwise injection analysis with a fluidizedbed reactor was applied to determination of glycerol in biodiesel involving in-line sample preparation (Shishov et al. 2016). After extracting the analyte in a mini-column filled with glass wool covered by adsorbed water, the extract was mixed with a cation exchanger saturated with $\mathrm{Cu}$ (II) under fluidized bed conditions. The copper glycerate formed on the surface of the floating particles was spectrophotometrically monitored.

Fluidized beds were also useful in the extraction and spectrophotometric quantification of gossypol in cottonseed meal (Daminato et al. 2017). The fluidized-bed mini-column was coupled to a flow system for the direct analysis of the solid samples under constant stirring, which favored interaction between the extractant and sample (25 $\mathrm{mg}$ accommodated in an acrylic mini-column). The coefficient of variation and sampling rate were estimated at $1.9 \%$ and $30 \mathrm{~h}^{-1}$, respectively.

\section{OPTOSENSING}

Optosensing is a kind of SPE, in which the adsorbed species are measured directly on a solid support, usuallybyspectrophotometry (eitherbytransmission or reflection), by vibrational spectrometry (Raman or infrared) or by luminescence (fluorescence or chemiluminescence). When spectrophotometric detection is exploited, the process is often termed solid-phase spectrophotometry. Fundamentals, characteristics, and applications of optosensing were critically reviewed (Rocha et al. 2011, Llorent-Martínez et al. 2015).
The higher analytical sensitivity inherent to optosensing results from the analyte accumulation on the solid phase, which usually presents a volume significantly lower than the sample. Measurements are performed before elution, thus avoiding the inherent dilution observed in other approaches for in-line analyte concentration. Other advantages include reduced reagent consumption and waste generation, as well as improved selectivity. The former characteristic is noted especially when the reagents are immobilized on the support and reversible retention of the analyte is feasible - the reagent is then reused in several cycles of analyte retention. The latter is provided by both separation of the analyte from the sample matrix or exploitation of differences on the sorption rates of the species on the solid support (Rocha et al. 2011). Although the process can be carried out batchwise, coupling to flow analysis has been preferred due to the highly reproducible conditioning of the solid support, sample loading, and elution. Analytical precision is then significantly improved and partial (yet reproducible) analyte sorption as well as continuous monitoring of the adsorption process aiming at kinetic discrimination can be exploited. Selection of suitable carrier streams for selective analyte retention can also be exploited for simultaneous determinations (Medina et al. 2000). On the other hand, the increase in backpressure due to the presence of solid particles in the flow cell should be taken into account, as this aspect may limit the flow-rates or the adsorbent amounts to be used. This hindrance has been circumvented either by adaptation of commercially available cells (Yoshimura 1987) or by using specially designed ones (Reis et al. 2000). Selection of suitable adsorbent characteristics (e.g. particle size) may also contribute to minimize backpressure.

Recent applications of optosensing include (i) fluorimetric determination of thiamethoxam in vegetables, by measuring the product of the in-line photodegradation, whose reversible 
accumulation into C18-bonded silica yielded a 10-fold improvement in sensitivity (JiménezLópez et al. 2016); (ii) direct fluorimetric analysis of urine exploiting molecularly imprinted xerogels as supports for accumulation of the cancer biomarker 5-hydroxyindole or the neurotransmitter serotonin aiming at improving the analytical selectivity and sensitivity (Dios et al. 2013); and (iii) determination of bromate in natural waters involving accumulation of the product of the reaction of the analyte with chlorpromazine on a cation exchange resin. In the latter application, in-line derivatization was carried out in a MSFIA system and, because of the reversible retention of the reaction product, up to 180 determinations were carried out with the same solid support (Oliveira et al. 2012). Other interesting innovation refers to combination of optosensing with bead injection, which permits the renewing of the solid support in every measurement cycle and expands significantly the application of the approach by encompassing irreversible systems. The feasibility of this proposal was demonstrated in the determination of proteins in wines carried out in a SIA-lab-on-valve system (Vidigal et al. 2012).

\section{MONOLITHIC AND FUSED-CORE COLUMNS}

SPE mini-columns can be used for low-pressure chromatographic separations for flow-based multicomponent determinations (Masini and Svec 2017). The strategy enhances the analytical potential by combining the versatility of flow techniques with the separation capacity of chromatography. This advance encompasses the use of monolithic and fused-core particles as illustrated in Fig. 2c.

Monoliths are constituted by a porous single piece of ultra-pure silica with macro and micro pores, providing high analyte separation efficiency with low backpressure, which enables their application in flow systems. Selectivity can be improved by bonding specific functional groups to the silica surface, such as octadecyl (C18) and cyano groups. From exploitation of monolithic columns in SIA the term sequential injection chromatography (SIC) was coined and the first application was focused on the determination of salicylic acid and methylsalicylate in pharmaceutical formulations (Huclová et al. 2003). Separation was carried out in a 50-mm long, $4.6 \mathrm{~mm}$ i.d. monolithic column with $\mathrm{C} 18$ bonded groups. The applications of SIC for analysis of pharmaceuticals and a comparison with HPLC were already reviewed (Chocholouš et al. 2007).

Monolithic phases have been also exploited in FIA systems with peristaltic pumps as fluid propulsion units. Because of the limited torque of these propelling devices in comparison to specially designed syringe pumps used in SIC, separations have been restricted to very short columns thus hindering the separation efficiency. More selective stationary phases are then needed. In the pioneer application, a 5-mm monolithic column was successfully exploited for separation of caffeine, theobromine, and theophylline in coffee (Santos and Rangel 2012).

Applicability of monoliths has been limited by the restricted number of commercially available stationary phases, but ingenious strategies have been proposed to circumvent this drawback. In this regard, stepwise elution allowed the complete separation of eighteen intracellular free amino acids from microalgae Tetraselmis gracilis using five different mobile phase compositions (Rigobello-Masini et al. 2008). Additionally, selectivity and detectability were improved by precolumn derivatization and fluorimetric detection. Strategies to modify stationary phase selectivity have also been presented, such as the use of micellar chromatography for in-line sample treatment and separation of melamine in milk (Batista et al. 2014). Chromatographic separation of melamine in C18 stationary phases is a difficult task due to its high polarity. Addition of an anionic surfactant to 
the mobile phase modifies the stationary phase by the interaction of their non-polar groups and yields micelles in the mobile phase thus altering the analyte partition and increasing selectivity. An additional advantage is the possibility of direct injection of relatively complex samples, such as milk. In this application, sample treatment involved a simple inline dilution with the surfactant solution.

Fused-core particles mini-columns also show high separation efficiency, low operational pressure, and are available in a variety of bonded phases. These particles are constituted by a solid core typically of fused silica impermeable to the analytes and to the mobile phase, covered by a thin external porous layer of stationary phase. The chromatographic efficiency is enhanced because of the faster analyte diffusion and the low variation in the particle size as observed with the small particles typically used in HPLC, but with a significant lower backpressure. The selectivity and separation capacity of fused-core columns in SIC were firstly evaluated in relation to seven phenolic acids (Chocholouš et al. 2013). Columns with different bonded phases $(30 \mathrm{~mm}$ x $4.6 \mathrm{~mm}$, particle size 2.7 $\mu \mathrm{m})$ were evaluated, and efficient resolution was achieved with RP-amide phase, whereas phenylhexyl and C18 mini-columns did not provide enough selectivity, highlighting the importance of appropriate stationary phase to compensate the use of short columns. This aspect was also emphasized by the use of guard $(5 \mathrm{~mm})$ fusedcore columns in FIA for separation of methyl-, ethyl- and propyl-parabens in daily care products (Batista and Rocha 2014). RP-amide led to the best separation efficiency compared to phenyl-hexyl and pentafluorophenylpropyl phases. Additionally to the low cost of these systems, the potentiality for sample treatment prior to chromatographic separation is a clear advantage. The feasibility of on-column concentration was demonstrated in a SIC procedure for separation of parabens (Batista and Rocha 2015). A high sample volume (up to 5.0
$\mathrm{mL}$ ) was inserted into a RP-amide fused-core minicolumn, followed by water. Because of the low eluent strength, analytes were retained in the top of the column. An acetonitrile plus phosphoric acid solution, $\mathrm{pH} 2.5(25: 75 \mathrm{v} / \mathrm{v})$ was used for elution and chromatographic separation. Enrichment factors of 435,405 , and 420 were achieved for metyl-, ethyl-, and propyl-parabens, respectively, demonstrating the potentialities of the proposed approach.

Introduction of fused-core columns allowed applications of SIC to more complex analytical problems, such as the determination of antibiotics in freshwaters. In this sense, a procedure coupling inline extraction and concentration of sulphonamides, followed by chromatographic separation in a fusedcore mini-column was developed (Batista et al. 2015). An ion-exchange resin was used for SPE of eight antibiotics, with elution and chromatographic separation on a pentafluorophenylpropyl phase carried out by the mobile phase (acetonitrile plus acetate buffer, $\mathrm{pH}$ 5.0).

\section{MOLECULARLY IMPRINTED SOLID PHASE EXTRACTION}

Solid phases used in flow systems commonly present poor selectivity and tend to adsorb a group of analytes with similar properties. Selectivity of the related methods has been improved either by exploiting an analyte derivatization reaction or by coupling a selective detector. As the availability of selective derivatization reactions is limited, selectivity needs to be improved by taking advantage of novel solid materials for selective adsorption.

Molecularly imprinted solid phase extraction (MISPE) is based on the use of molecularly imprinted polymers (MIP), which are very selective solid phases with abilities of molecular recognition resulting from the molecular impression during their synthesis. A schematic representation of preparation and operation of a MIP for selective 
SPE is shown in Fig. 2d. The use of MIPs solid phases in flow systems was emphasized in a critical review (Dias et al. 2008).

Bulk polymerization is the usual procedure for MIP production, in which functional monomers, template molecules, and a cross-linker reagent are added to form a polymer block. Thereafter, the template molecules are removed from the polymer to create a molecularly impressed site. Methacrylic acid (MAA) and ethylene glycol dimethacrylate (EGDMA) are often used as functional monomer and cross-linker, respectively. Most applications have been focused on the determinations of organic analytes in biological samples, which is a difficult task in flow analysis without a selective sorbent.

As a representative example, a MIP sorbent for epinephrine was developed using MAA and EGDMA (Du et al. 2003), aiming at its chemiluminometric determination. The sorbent was packed into a flow cell placed close to the detector. After selective sorption of the analyte, solutions of luminol and potassium hexacyanoferrate(III) were injected into the system and reacted with the epinephrine adsorbed on the MIP yielding the chemiluminescence. LOD was estimated at 3 $\mathrm{nmol} \mathrm{L}{ }^{-1}$, which is suitable for the direct analysis of serum samples. This application illustrates the use of MISPE to improve performance when poorly selective detection is involved or when matrix effects are relevant, such as in the chemiluminometric analysis of biological and environmental samples.

An imprinted polymer for terbutaline extraction prepared with MAA and EGDMA was used in a micro-flow system (He et al. 2006). The chip was built up with two poly(methylmethacrylate) parts with $200 \mu \mathrm{m}$ wide and $150 \mu \mathrm{m}$ deep microchannels. The sorbent $(2.0 \mathrm{mg})$ was placed into a $100-\mathrm{mm}$ long chamber. The determination relied on the chemiluminescence produced by the reaction of terbutaline with luminol and potassium hexacyanoferrate(III). With $720 \mu \mathrm{L}$ of sample, the procedure presented a LOD of $4.0 \mathrm{ng} \mathrm{mL}^{-1}$; the high sensitivity and low sample amount required make the procedure attractive for biological analysis. However, the low flow rate and the need for a cleaning step reduced sampling rate $\left(7 \mathrm{~h}^{-1}\right)$. Additionally, the chip should be replaced after $c a$. 100 determinations due to the lessening of the MIP efficiency.

Because of the improved selectivity, simpler flow manifolds can be achieved by exploiting MISPE. For example, a single-channel manifold was proposed for the fluorimetric determination of 1-hydroxypyrene in urine involving in-line extraction and concentration in a MIP sorbent (Serrano et al. 2017). Because of the complexity of the matrix and the low levels of the analyte in the samples, effective sample clean-up and analyte concentration were needed. The sorbent was prepared with MAA and EGDMA and packed into a $1.8-\mathrm{cm}$ long, $0.8-\mathrm{mm}$ i.d. mini-column. For $250 \mu \mathrm{L}$ of sample, LOD was estimated at $3.1 \mu \mathrm{g}$ $\mathrm{L}^{-1}$. Enhancement of selectivity and detectability provided by the selective SPE, the high sensitivity of fluorimetric detection, as well as the versatility and high sampling rate provided by flow analysis make the proposal an outstanding approach.

The advantages of coupling MISPE to flow systems were also highlighted in the determination of florfenicol in liver, pork, chicken, and fish tissues (Ge et al. 2010). The MIP was prepared with acrylamide and EGDMA. After extraction and concentration, the analyte was eluted from the sorbent and quantified by the inhibition of the chemiluminescence from the reaction of 3-p-nitrylphenyl-5-(2'-sulfonophenylazo) rhodamine and bovine serum albumin. Sample treatment included extraction with water and acetone and injection of $1.5 \mathrm{~mL}$ of the extract into the flow system. Elution from the MIP mini-column was accomplished with a methanol/acetic acid/ sodium dodecyl sulfate (SDS) solution. A LOD of $34 \mathrm{ng} \mathrm{mL} \mathrm{mL}^{-1}$ was achieved with a relative standard 
deviation of $3.5 \%$. The results agreed with those obtained by HPLC.

MISPE was also exploited in a flow system for in-line concentration of $\mathrm{Hg}$ (II) in water and human hair followed by derivatization with dithizone and spectrophotometric detection (Rajabi et al. 2015). The procedure provided an EF of 160 and a LOD of $0.036 \mathrm{ng} \mathrm{mL}^{-1}$. MISPE was also performed with nanoparticles for extraction and concentration of $\mathrm{Zn}^{2+}$ (Fereidoonipour and Rajabi 2017). The nanoparticles were synthetized from a stable $\mathrm{Zn}^{2+}$ chelate with 3,5,7,2',4'-pentahydroxyflavone copolymerized with MAA, in the presence of EGDMA. Spectrophotometric detection was carried out after formation of the colored $\mathrm{Zn}$ (II) dithizonate complex, with LOD of $400 \mathrm{nmol} \mathrm{L}^{-1}$ and EF of 117. Other relevant applications refer to the chemiluminometric determination of isoniazid in urine (Xiong et al. 2007) as well as amperometric determination of 4-nitrophenol in water (Gholivand et al. 2015) and traces of cadmium in jewelry, black and green tea, tobacco and hair (Lago et al. 2016). Additionally to advantages provided by the use of MIP, the performance of these procedures was improved by using MCFA, because of the independent implementation of the steps involved in sample processing.

\section{BIOSORBENTS}

Effective analyte separation/concentration and sample clean-up in SPE relies on the suitable choice of the adsorbent material. Usually, solid phases are based on silica or organic polymers functionalized with different ligands, selected in accordance to the target analytes. In general, these materials are relatively expensive and discarded after batchwise procedures. Flow-based techniques usually allow the reuse of the adsorbent material, besides using amounts significantly lower than batchwise. Biosorbents, a suitable alternative to synthetic materials, are usually obtained from plants or microorganisms (e.g. seeds and fungi) and some materials are widely available as industrial wastes. Advantages of these materials include low cost, extensive availability, and improved selectivity in comparison to synthetic sorbents. Additionally, consumption of reagents in their synthesis is avoided, although chemical modification is sometimes required to improve selectivity or sorption efficiency.

Biosorbents in flow systems may lead to improved sample throughput. The rigorous time control on the sample processing makes feasible the exploitation of non-exhaustive extractions and kinetic discrimination. Applications have been mainly focused on metal determinations by atomic spectrometry, as recently reviewed (Teixeira et al. 2016). The determination of $\mathrm{Cr}$ (III) and $\mathrm{Cr}$ (VI) in water involving Saccharomyces cerevisiae as sorbent is an illustrative example (Menegário et al. 2005). The fungi cells were immobilized on controlled pore glass and packed into a 2.3$\mathrm{mm}$ long mini-column (4 mm i.d.). Chromium speciation was based on the biosorption of $\mathrm{Cr}$ (III) and $\mathrm{Cr}(\mathrm{VI})$ retention on pore glass. Selective $\mathrm{Cr}(\mathrm{III})$ and $\mathrm{Cr}(\mathrm{VI})$ elutions were achieved with 0.05 mol L ${ }^{-1} \mathrm{HCl}$ and $2.0 \mathrm{~mol} \mathrm{~L}^{-1} \mathrm{HNO}_{3}$, respectively. Analyte accumulation provided by biosorption lead to LODs of 0.45 and $1.5 \mu \mathrm{g} \mathrm{L}^{-1}$ for $\mathrm{Cr}$ (III) and $\mathrm{Cr}(\mathrm{VI})$, with preconcentration factors of 12 and 5, respectively. Biosorbents based on Saccharomyces cerevisiae are cheap, easily obtained, and able to be reused for up to 120 analyses without efficiency loss. Other applications of microorganisms as biosorbents in flow systems include the separation/ concentration of $\mathrm{Pb}$ (II) from tap and seawater by filamentous fungi supported on $\mathrm{TiO}_{2}$ nanoparticles (Bakircioglu et al. 2010) and use of Saccharomyces cerevisiae immobilized on calcium alginate beads for determining $\mathrm{Pt}(\mathrm{IV})$ in spiked grass, road dust or water samples in a FIA system with FAAS or chemiluminescence detection (GodlewskaŻyłkiewicz et al. 2008). 
Vermicompost is a product of organic matter degradation by earthworms commonly used as a fertilizer. The high content of humic substances provides high cation exchange and sorption capacities. The vermicompost presents a longer lifetime in comparison to other sorbents based on microorganisms. This material is then a suitable option for separation/concentration of metals in flow systems, as demonstrated in the determination of $\mathrm{Cd}$ (II) in ethanol fuel by FAAS (Bianchin et al. 2009). With 160 mgofbiosorbent, a preconcentration factor of 32, a sample consumption of $10 \mathrm{~mL}$ per determination, and a sampling rate of $20 \mathrm{~h}^{-1}$ were attained. Additionally, the biosorbent could be reused for more than 150 times without loss of efficiency. Vermicompost was also used for the extraction and concentration of $\mathrm{Cd}(\mathrm{II})$ and $\mathrm{Pb}$ (II) from mineral waters, pharmaceutical preparations, fruit juices, pig kidney, and beech leaves (Pereira and Arruda 2004). The sorption efficiency was affected by $\mathrm{Ca}^{2+}, \mathrm{Mg}^{2+}, \mathrm{Na}^{+}$, and $\mathrm{K}^{+}$due to the high cationic exchange capacity of the biosorbent.

Biosorbents based on plant tissues have also been exploited for SPE of metals in flow analysis. In this context, Moringa oleifera seeds have been used as an ion-exchanger in the determinations of several metal ions, such as e.g. $\operatorname{Ag}(\mathrm{I})$ in water in a flow system with FAAS detection (Araújo et al. 2010). Preparation of the biosorbent involved only drying, blending, and sieving of the seeds. An EF of 35 was achieved with $35 \mathrm{mg}$ of biosorbent with a sampling rate of $12 \mathrm{~h}^{-1}$ and a sample consumption of $14 \mathrm{~mL}$ per determination.

\section{MAGNETIC MATERIALS}

Magnetic particles have been efficiently exploited for SPE in flow analysis, as their movement can be efficiently controlled by means of external magnetic fields (e.g. dispersion of the sorbent into the sample and removal from the liquid medium). These materials can be dispersed in a large volume of sample, thus increasing the surface area and the number of available adsorption sites (Maya et al. 2017). Magnetic materials have been used with 1-100 nm nanoparticles, particularly of $\mathrm{Fe}_{3} \mathrm{O}_{4}$, $\mathrm{MnFe}_{2} \mathrm{O}_{4}$, and $\mathrm{CoFe}_{2} \mathrm{O}_{4}$ (Beveridge et al. 2011). Applications involve different analytes (e.g. metal ions, estrogens, and surfactants) in a diversity of samples (e.g. water, urine, and human hair) with different analytical techniques (e.g. UV-Vis, ETAAS, and GC-MS), including in situ analysis (Passos et al. 2015). The main characteristics of this approach are illustrated by selected applications.

Magnetic nanoparticles functionalized with 1,5-bis(di-2-pyridil)methylene thiocarbohydrazide were used for in-line separation and concentration of $\mathrm{Hg}$ aiming at its determination in biological materials and sea water by ETAAS with a cold vapour generation system (Alonso et al. 2016). Drawbacks such as increased backpressure and manifold clogging were circumvented by the proposed approach. The sorbent lifetime and sampling rate were estimated as 550 cycles and $16 \mathrm{~h}^{-1}$, respectively, demonstrating the potential of magnetic beads exploitation for large-scale determinations.

Flow-injection chemiluminometric determination of chrysoidine in food samples exploited $\mathrm{Fe}_{3} \mathrm{O}_{4} @ \mathrm{SiO}_{2}$ magnetic nanoparticles with MIPs at the particle surface ( $\mathrm{Lu}$ et al. 2012). The selectivity was up to 100 -fold better in relation to the analogous procedure without SPE. Furthermore, the washing step was in-line accomplished, allowing the sensor reuse.

The advantageous reuse of a mini-column was also evident in an automated SIA system with magnetic sorbent extraction coupled to ETAAS for $\mathrm{Cd}$ determination in natural waters (Giakisikli and Anthemidis 2013). The mini-column with octadecylsilane functionalized maghemite magnetic particles remained stable during more than 600 cycles, thus reducing the analytical cost and facilitating the use in routine analyses. 
A SIA system coupled to GFAAS was proposed for $\mathrm{Cd}$ determination by exploiting a modified sorbent based on magnetic multiwalled carbon nanotubes with iron oxide on the surface (Wang et al. 2016). The improvement in sensitivity was noteworthy, with LOD and EF estimated at 1.2 ng $\mathrm{L}^{-1}$ and 160, respectively. The sorbent could be reused up to 100 times without degradation.

Magnetic multiwalled carbon nanotubes were used for in-line $\mathrm{Cr}$ (III) separation/concentration. A syringe pump was used for insertion of the treated sample solution into a microfluidic chip for in-line derivatization and monitoring of the laser-induced fluorescence (Peng et al. 2017). High selectivity was achieved, EF was estimated at 38, and drastic reduction of the amount of chemical reagent was noted.

Submicrometric magnetic nanoporous carbons derived from metal-organic frameworks were recently proposed as sorbent in SIA (Frizzarin et al. 2016). The set-up included a three-dimensional printed holder with an automatically actuated electromagnet. Extraction of SDS after ion pair formation with methylene blue was selected as a model. The material showed advantages as high contact area and stability; moreover, use of the electromagnet improved the repeatability and the extraction efficiency.

The magnetic porous carbon derived from zeolitic imidazolate frameworks was used in syringe magnetic dispersive micro-solid phase extraction (González et al. 2017). The particles were dispersed in the sample by agitation and further attracted towards a magnetic bar. Sample clean-up and estrogen accumulations required less than $20 \mathrm{~min}$ and a low amount $(300 \mu \mathrm{L})$ of organic solvent.

\section{CONCLUSIONS AND TRENDS}

Amazing conceptual, methodological, and applicative advances in flow-based analytical approaches involving in-line SPE were emphasized in this review. These involve the development of novel materials, exploitation of different flow modalities, and applications to solve a diversity of analytical problems, either by analyte separation/concentration or sample clean-up. Some applications have been focused on analyte fractionation or chemical speciation, but studies on this issue are still needed.

In recent years, the number of applications relying on direct measurements on solid supports has been increasing as a consequence of the absence of sample dilution inherent to the elution step, the feasibility of exploiting kinetic aspects related to the sorption processes, as well as the reversible analyte sorption. Novel approaches have been proposed to circumvent drawbacks such as swelling, preferential pathways, and increased backpressure (e.g. by exploiting moving beads or fluidized beds) and to improve sample throughput (e.g. by simultaneously carrying out several processes). Coupling chromatographic solid phases to flow techniques has expanded the applicability range and the analytical selectivity.

Some foreseen trends are: (i) improvement of the sorption efficiency by exploiting nanomaterials or sorbent dispersion by fluidized beds, including use of magnetic sorbents; (ii) development of selective sorbents and/or materials for low pressure chromatographic separations; (iii) exploitation of flow-based SPE for sample treatment before chromatographic separations; (iv) miniaturization aiming at portable devices requiring minute amounts of reagents and eluents, thus despicable waste volumes; and (v) applications involving bioanalysis. In view of this scenario, exploitation of SPE stands out by one of the most fertile field in the future research in analysis. 


\section{ACKNOWLEDGMENTS}

Fellowships and financial support from Fundação de Amparo à Pesquisa do Estado de São Paulo (FAPESP, proc. 2011/23498-9) and Conselho Nacional de Desenvolvimento Científico e Tecnológico $(\mathrm{CNPq})$ are greatly appreciated.

\section{REFERENCES}

ALONSO EV, GUERRERO MML, CUETO PC, BENÍTEZ JB, PAVÓN JMC AND TORRES AG. 2016. Development of an on-line solid phase extraction method based on new functionalized magnetic nanoparticles. Use in the determination of mercury in biological and sea-water samples. Talanta 153: 228-239.

AMPAN P, LAPANANTNOPPAKHUN S, SOOKSAMITI P, JAKMUNEE J, KRADTAP HARTWELL S, JAYASVATI S, CHRISTIAN GD AND GRUDPAN K. 2002. Determination of trace iron in beer using flow injection systems with in-valve column and bead injection. Talanta 58: 1327-1334.

ARAÚJO CST, ALVES VN, REZENDE HC AND COELHO NMM. 2010. Development of a flow system for the determination of low concentrations of silver using Moringa oleifera seeds as biosorbent and flame atomic absorption spectrometry. Microchem J 96: 82-85.

ARTHUR CL AND PAWLISZYN J. 1990. Solid phase microextraction with thermal desorption using fused silica optical fibers. Anal Chem 62: 2145-2148.

BAKIRCIOGLU Y, BAKIRCIOGLU D AND AKMAN S. 2010. Biosorption of lead by filamentous fungal biomassloaded $\mathrm{TiO}_{2}$ nanoparticles. J Hazard Mater 178: 10151020.

BATISTA AD, CHOCHOLOUS P, SATÍNSKÝ D, SOLICH P AND ROCHA FRP. 2015. On-line hyphenation of solid-phase extraction to chromatographic separation of sulfonamides with fused-core columns in sequential injection chromatography. Talanta 133: 142-149.

BATISTA AD, NASCIMENTO CF, MELCHERT WR AND ROCHA FRP. 2014. Expanding the separation capability of sequential injection chromatography: Determination of melamine in milk exploiting micellar medium and on-line sample preparation. Microchem J 117: 106-110.

BATISTA AD AND ROCHA FRP. 2014. A flow injection lowpressure chromatographic system exploiting fused-core columns. Anal Methods 6: 9299-9304.

BATISTA AD AND ROCHA FRP. 2015. On-column preconcentration in sequential injection chromatography: application to determination of parabens. Anal Methods 7: 4371-4375.
BELARDI RP AND PAWLISZYN JB. 1989. The application of chemically modified fused silica fibers in the extraction of organics from water matrix samples and their rapid transfer to capillary columns. Water Qual Res J Can 24: 179-191.

BERGAMIN-FILHO H, REIS BF, JACINTHO AO AND ZAGATTO EAG. 1980. Ion exchange in flow injection analysis. Anal Chim Acta 117: 81-89.

BERGAMIN-FILHO H, ZAGATTO EAG, KRUG FJ AND REIS BF. 1978. Merging zones in flow injection analysis. Part 1. Double proportional injector and reagent consumption. Anal Chim Acta 101: 17-23.

BEVERIDGE JS, STEPHENS JR AND WILLIAMS ME. 2011. The use of magnetic nanoparticles in analytical chemistry. Annu Rev Anal Chem 4: 251-273.

BIANCHIN JN, MARTENDAL E, MIOR R, ALVES VN, ARAÚJO CST, COELHO NMM AND CARASEK E. 2009. Development of a flow system for the determination of cadmium in fuel alcohol using vermicompost as biosorbent and flame atomic absorption spectrometry. Talanta 78: 333-336.

BOONJOB W. 2014. An overview about recent advances of micro-solid phase extraction in flow based techniques. Austin J Anal Pharm Chem 1: 1006-1011.

BOONJOB W, SKLENÁROVÁ H, BARRON L, SOLICH P AND SMITH N. 2015. Renewable sorbent material for solid phase extraction with direct coupling of sequential injection analysis-bead injection to liquid chromatographyelectrospray ionization tandem mass spectrometry. Anal Bioanal Chem 407: 5719-5728.

BRUNETTO MDR, CLAVIJO S, DELGADO Y, OROZCO W, GALLIGNANI M, AYALA C AND CERDÀ V. 2015. Development of a MSFIA sample treatment system as front end of GC-MS for atenolol and propranolol determination in human plasma. Talanta 132: 15-22.

BURGUERA JL, BURGUERA M AND TOWNSHEND A. 1981. Determination of zinc and cadmium by flow injection analysis and chemiluminescence. Anal Chim Acta 127: 199-201.

BUSZEWSKI B AND SZULTKA M. 2012. Past, present, and future of solid phase extraction: A Review. Crit Rev Anal Chem 42: 198-213.

CHISVERT A, VIDAL MT AND SALVADOR A. 2002. Sequential injection analysis for benzophenone-4 and phenylbenzimidazole sulphonic acid in sunscreen sprays by solid-phase extraction coupled with ultraviolet spectrometry. Anal Chim Acta 464: 295-301.

CHOCHOLOUS P, SOLICH P AND SATÍNSKÝ D. 2007. An overview of sequential injection chromatography. Anal Chim Acta 600: 129-135.

CHOCHOLOUS P, VACKOVÁ J, SRÁMKOVÁ I, SATÍNSKÝ D AND SOLICH P. 2013. Advantages of core-shell particle columns in Sequential Injection 
Chromatography for determination of phenolic acids. Talanta 103: 221-227.

CHOMCHOEI R, MIRÓ M, HANSEN EH AND SHIOWATANA J. 2005. Sequential injection system incorporating a micro-extraction column for automatic fractionation of metal ions in solid samples: Comparison of the extraction profiles when employing uni-, bi-, and multi-bi-directional flow plus stopped-flow sequential extraction modes. Anal Chim Acta 536: 183-190.

DAMINATO B, KAMOGAWA MY AND MELCHERT WR. 2017. An environmental friendly flow-injection procedure for on line extraction and spectrophotometric determination of gossypol in cottonseed meal. J Braz Chem Soc 28: 2094-2099.

DIAS ACB, BORGES EP, ZAGATTO EAG AND WORSFOLD PJ. 2006. A critical examination of the components of the Schlieren effect in flow analysis. Talanta 68: 1076-1082.

DIAS ACB, FIGUEIREDO EC, GRASSI V, ZAGATTO EAG AND ARRUDA MAZ. 2008. Molecularly imprinted polymer as a solid phase extractor in flow analysis. Talanta 76: 988-996.

DIOS AS, BADÍA-LAÍÑO R AND DÍAZ-GARCÍA ME. 2013. Cancer biomarker and neurotransmitters recognition by molecularly imprinted xero-gels. Sensor Actuat B-Chem 184: 48-53.

DU J, SHEN L AND LU J. 2003. Flow injection chemiluminescence determination of epinephrine using epinephrine-imprinted polymer as recognition material. Anal Chim Acta 489: 183-189.

ECONOMOU A. 2005. Sequential-injection analysis (SIA): A useful tool for on-line sample-handling and pre-treatment. Trends Analyt Chem 24: 416-425.

EL-SHAHAT MF, BURHAM N AND AZEEM SMA. 2010. Flow injection analysis-solid phase extraction (FIASPE) method for preconcentration and determination of trace amounts of penicillins using methylene blue grafted polyurethane foam. J Hazard Mater 177: 1054-1060.

FANGZ. 1993. Flow Injection Separation and Preconcentration, $\mathrm{VCH}$, Weinheim, $259 \mathrm{p}$.

FANG Z, RUZICKA J AND HANSEN EH. 1984. An efficient flow-injection system with on-line ion-exchange preconcentration for the determination of trace amounts of heavy metals by atomic absorption spectrometry. Anal Chim Acta 164: 23-39.

FEREIDOONIPOUR F AND RAJABI HR. 2017. Development of flow injection analysis-solid phase extraction based on ion imprinted polymeric nanoparticles as an efficient and selective technique for preconcentration of zinc ions from aqueous solution. New J Chem 41: 8828-8836.
FERNÁNDEZ M, FORTEZA R AND CERDÁ V. 2012. Monolithic columns in flow analysis: a review of SIC and FIC techniques. Instrum Sci Technol 40: 90-99.

FERREIRA SLC, JESUS DS, CASSELLA RJ, COSTA ACS, CARVALHO MS AND SANTELLI RE. 1999. An on-line solid phase extraction system using polyurethane foam for the spectrophotometric determination of nickel in silicates and alloys. Anal Chim Acta 378: 287-292.

FRIZZARIN RM, CABELLO CP, BAUZÀ MDM, PORTUGAL LA, MAYA F, CERDÀ V, ESTELA JM AND PALOMINO GT. 2016. Submicrometric magnetic nanoporous carbons derived from metal-organic frameworks enabling automated electromagnet-assisted online solid-phase extraction. Anal Chem 88: 6990-6995.

GALES ME, KAYLOR WH AND LONGBOTTOM JE. 1968. Determination of sulphate by automatic colorimetric analysis. Analyst 93: 97-100.

GAŁUSZKA A, MIGASZEWSKI Z AND NAMIEŚNIK J. 2013. The 12 principles of green analytical chemistry and the SIGNIFICANCE mnemonic of green analytical practices. Trends Analyt Chem 50: 78-84.

GE S, YAN M, CHENG X, ZHANG C, YU J, ZHAO P AND GAO W. 2010. On-line molecular imprinted solidphase extraction flow-injection fluorescence sensor for determination of florfenicol in animal tissues. J Pharm Biomed Anal 52: 615-619.

GHANI M, MAYA F AND CERDA V. 2016a. Automated solid-phase extraction of organic pollutants using melamine-formaldehyde polymer-derived carbon foams. RSC Advances 6: 48558-48565.

GHANI M, SARAJI M, MAYA F AND CERDÀ V. 2016 b. Automated multisyringe stir bar sorptive extraction using robust montmorillonite/epoxy-coated stir bars. J Chromatogr A 1445: 10-18.

GHOLIVAND MB, KHODADADIAN M AND BAHRAMI G. 2015. Molecularly imprinted polymer preconcentration and flow injection amperometric determination of 4-nitrophenol in water. Anal Lett 48: 2856-2869.

GIAKISIKLI G AND ANTHEMIDIS AN. 2013. Automated magnetic sorbent extraction based on octadecylsilane functionalized maghemite magnetic particles in a sequential injection system coupled with electrothermal atomic absorption spectrometry for metal determination. Talanta 110: 229-235.

GODLEWSKA-ZYLKIEWICZ B, MALEJKO J, LESNIEWSKA B AND KOJLO A. 2008. Assessment of immobilized yeast for the separation and determination of platinum in environmental samples by flow-injection chemiluminescence and electrothermal atomic absorption spectrometry. Microchim Acta 163: 327-334.

GOMES-NETO JA, BERGAMIN-FILHO H, SARTINI RP AND ZAGATTO EAG. 1995. Determination of cadmium in foodstuffs and plant materials by flow injection- 
spectrophotometry including ion exchange. Anal Chim Acta 306: 343-349.

GONZÁLES APS, FIRMINO MA, NOMURA CS, ROCHA FRP, OLIVEIRA PV AND GAUBEUR I. 2009. Peat as a natural solid-phase for copper preconcentration and determination in a multicommuted flow system coupled to flame atomic absorption spectrometry. Anal Chim Acta 636: 198-204.

GONZÁLEZ A, AVIVAR J, MAYA F, CABELLO CP, PALOMINO GT AND CERDÀ V. 2017. In-syringe dispersive $\mu$-SPE of estrogens using magnetic carbon microparticles obtained from zeolitic imidazolate frameworks. Anal Bioanal Chem 409: 225-234.

HANSEN EH AND RUZICKA J. 1983. FIA is already a routine tool in Brazil. Trends Analyt Chem 2: V-VII.

HE D, ZHANG Z, ZHOU H AND HUANG Y. 2006. Micro flow sensor on a chip for the determination of terbutaline in human serum based on chemiluminescence and a molecularly imprinted polymer. Talanta 69: 1215-1220.

HORSTKOTTE B, CHOCHOLOUŠ P AND SOLICH P. 2016. Large volume preconcentration and determination of nanomolar concentrations of iron in seawater using a renewable cellulose 8-hydroquinoline sorbent microcolumn and universal approach of post-column eluate utilization in a Lab-on-Valve system. Talanta 150: 213-223.

HUCLOVÁ J, ŠATÍNSKÝ D, AND KARLÍCEK R. 2003. Coupling of monolithic columns with sequential injection technique. Anal Chim Acta 494: 133-140.

JIMÉNEZ-LÓPEZ J, ORTEGA-BARRALES P AND RUIZMEDINAA. 2016. Development of an semi-automatic and sensitive photochemically induced fluorescence sensor for the determination of thiamethoxam in vegetables. Talanta 149: 149-155.

KAMSON OF AND TOWNSHEND A. 1983. Ion-exchange removal of some interferences on the determination of calcium by flow injection analysis and atomic absorption spectrometry. Anal Chim Acta 155: 253-257.

LAGO ACD, MARCHIONI C, MENDES TV, WISNIEWSKI C, FADINI PS AND LUCCAS PO. 2016. Ion imprinted polymer for preconcentration and determination of ultra-trace cadmium, employing flow injection analysis with thermo spray flame furnace atomic absorption spectrometry. Appl Spectrosc 70: 1842-1850.

LIU Y AND INGLE JD. 1989. Automated two-column ion exchange system for determination of the speciation of trace metals in natural waters. Anal Chem 61: 525-529.

LLORENT-MARTÍNEZ EJ, CÓRDOVA MLF, ORTEGABARRALES P AND RUIZ-MEDINA A. 2015. Analysis of agroalimentary and environmental contaminants using flow-through chemical optosensors. Appl Spectrosc Rev 50: 527-556.
LU F, SUN M, FAN L, QIU H, LI X AND LUO C. 2012. Flow injection chemiluminescence sensor based on coreshell magnetic molecularly imprinted nanoparticles for determination of chrysoidine in food samples. Sensor Actuat B-Chem 173: 591-598.

MACHADO JMC, MELCHERT WR, ZAGATTO EAG AND KAMOGAWA MY. 2017. A multi-pumping flow system with pulsed fluidization to evaluate soil capacity for phosphate adsorption. J Braz Chem Soc 28: 1149-1157.

MAGALHÃES LO AND FONSECA A. 2017. A microfluidic device with ion-exchange preconcentration column and photometric detection with Schlieren effect correction. Microchem J 132: 161-166.

MANIASSO N, ZAGATTO EAG AND SANTELLI RE. 1996. A new approach for compensating concentration gradients in flow analysis. Anal Chim Acta 331: 17-22.

MASINI JC AND SVEC F. 2017. Porous monoliths for on-line sample preparation: A review. Anal Chim Acta 964: 24-44.

MAYA F, CABELLO CP, FRIZZARIN RM, ESTELA JM, PALOMINO GT AND CERDÀ V. 2017. Magnetic solidphase extraction using metal-organic frameworks (MOFs) and their derived carbons. Trends Analyt Chem 90: 142152.

MEDINAAR, CÓRDOVA MLF, CAÑADA MJA, REGUERA MIP AND DÍAZ AM. 2000. A flow-through solid phase UV spectrophotometric biparameter sensor for the sequential determination of ascorbic acid and paracetamol. Anal Chim Acta 404: 131-139.

MELCHERT WR AND ROCHA FRP. 2005. A green analytical procedure for flow-injection determination of nitrate in natural waters. Talanta 65: 461-465.

MENEGÁRIO AA, SMICHOWSKI P AND POLLA G. 2005. On-line preconcentration and speciation analysis of $\mathrm{Cr}$ (III) and $\mathrm{Cr}(\mathrm{VI})$ using baker's yeast cells immobilised on controlled pore glass. Anal Chim Acta 546: 244-250.

MIRANDA CES, REIS BF, BACCAN N, PACKER AP AND GINÉ MF. 2002. Automated flow analysis system based on multicommutation for $\mathrm{Cd}, \mathrm{Ni}$ and $\mathrm{Pb}$ on-line pre-concentration in a cationic exchange resin with determination by inductively coupled plasma atomic emission spectrometry. Anal Chim Acta 453: 301-310.

MIRANDA CES, REIS BF AND KRUG FJ. 1995. A flow injection system with four ion exchange resin columns for cadmium pre-concentration and determination by flame AAS. J Braz Chem Soc 6: 387-392.

MIRÓ M, CERDÀ VC AND ESTELA JM. 2002. Multisyringe flow injection analysis: characterization and applications. Trends Analyt Chem 21: 199-210.

MIRÓ M, CLADERA A, ESTELA JM AND CERDA V. 2000. Sequential injection spectrophotometric analysis of nitrite in natural waters using an on-line solid-phase extraction and preconcentration method. Analyst 125: 943-948. 
MIRÓ M, HARTWELL SK, JAKMUNEE J, GRUDPAN K AND HANSEN EH. 2008. Recent developments in automatic solid-phase extraction with renewable surfaces exploiting flow-based approaches. Trends Analyt Chem 27: 749-761.

OLIVEIRA HM, MIRÓ M, SEGUNDO MA AND LIMA JLFC. 2011. Universal approach for mesofluidic handling of bead suspensions in lab-on-valve format. Talanta 84 : 846-852.

OLIVEIRA SM, OLIVEIRA HM, SEGUNDO MA, RANGEL AOSS, LIMA JLFC AND CERDA V. 2012. Automated solid-phase spectrophotometric system for optosensing of bromate in drinking waters. Anal Methods 4: 1229-1236.

OLIVEIRA TF, OLIVEIRA FM, SEGATELLI MG AND TARLEY CRT. 2013. Evaluation of poly(vinylpyridine)supported protoporphyrin resin for the sampling/separation of manganese(II) using a hyphenated FIA-FAAS system. Anal Methods 5: 3264-3271.

PASSOS MLC, PINTO PCAG, SANTOS JLM, SARAIVA MLMFS AND ARAUJO ARTS. 2015. Nanoparticle-based assays in automated flow systems: A review. Anal Chim Acta 889: 22-34.

PENG G, HE Q, LU Y, HUANG J AND LIN JM. 2017. Flow injection microfluidic device with on-line fluorescent derivatization for the determination of $\mathrm{Cr}(\mathrm{III})$ and $\mathrm{Cr}(\mathrm{VI})$ in water samples after solid phase extraction. Anal Chim Acta 955: 58-66.

PEREIRA MG AND ARRUDA MAZ. 2004. Preconcentration of $\mathrm{Cd}(\mathrm{II})$ and $\mathrm{Pb}$ (II) using humic substances and flow systems coupled to flame atomic absorption spectrometry. Microchim Acta 146: 215-222.

PONS C, MIRÓ M, BECERRA E, ESTELA JM AND CERDÀ VC. 2004. An intelligent flow analyser for the in-line concentration, speciation and monitoring of metals at trace levels. Talanta 62: 887-895.

PONS C, FORTEZA R AND CERDÀ V. 2005. The use of anion-exchange disks in an optrode coupled to a multisyringe flow-injection system for the determination and speciation analysis of iron in natural water samples. Talanta 66: 210-217.

RAJABI HR, SHAMSIPUR M, ZAHEDI MM AND ROUSHANI M. 2015. On-line flow injection solid phase extraction using imprinted polymeric nanobeads for the preconcentration and determination of mercury ions. Chem Eng J 259: 330-337.

RAMA MJR, MEDINA AR AND DÍAZ AM. 2003. Bead injection spectroscopic flow-through renewable surface sensors with commercial flow cells as an alternative to reusable flow-through sensors. Anal Chim Acta 482: 209217.

REIS BF, JACINTHO AO, MORTATTI J, KRUG FJ, ZAGATTO EAG, BERGAMIN-FILHO H AND
PESSENDA LCR. 1981. Zone-sampling processes in flow injection analysis. Anal Chim Acta 123: 221-228.

REIS BF, ROCHA FRP, TEIXEIRA LSG, COSTA ACS AND KORN M. 2000. Construction of a flow cell for measurement by solid phase spectrophotometry. Quim Nova 23: 116-118.

RENDL M, BRANDSTETTER T AND RÜHE J. 2014. Solidphase extraction in segmented flow. Langmuir 30: 1280412811.

RIBEIRO MFT, DIAS ACB, SANTOS JLM, LIMA JLFC AND ZAGATTO EAG. 2006. Fluidized beds in flow analysis: use with ion-exchange separation for spectrophotometric determination of zinc in plant digests. Anal Bioanal Chem 384: 1019-1024.

RIGOBELLO-MASINI M, PENTEADO JCP, LIRIA CW, MIRANDA MTM AND MASINI JC. 2008. Implementing stepwise solvent elution in sequential injection chromatography for fluorimetric determination of intracellular free amino acids in the microalgae Tetraselmis gracilis. Anal Chim Acta 628: 123-132.

ROCHA FRP, MARTELLI PB AND REIS BF. 2004. Simultaneous in-line concentration for spectrophotometric determination of cations and anions. J Braz Chem Soc 15: 38-42.

ROCHA FRP, MARTELLI PCB AND REIS BF. 2001. An improved flow system for spectrophotometric determination of anions exploiting multicommutation and multidetection. Anal Chim Acta 438: 11-19.

ROCHA FRP, RAIMUNDO IM AND TEIXEIRA LSG. 2011. Direct solid-phase optical measurements in flow systems: A Review. Anal Lett 44: 528-559.

ROCHA FRP, REIS BF, ZAGATTO EAG, LIMA JLFC, LAPA RAS AND SANTOS JLM. 2002. Multicommutation in flow analysis: concepts, applications and trends. Anal Chim Acta 468: 119-131.

ROSENDE M, MIRÓ M AND CERDÀ V. 2010. Fluidizedbed column method for automatic dynamic extraction and determination of trace element bioaccessibility in highly heterogeneous solid wastes. Anal Chim Acta 658: 41-48.

RUZICKA J AND HANSEN EH. 1975. Flow injection analyses. Anal Chim Acta 78: 145-157.

RUZICKA J AND SCAMPAVIA L. 1999. Peer reviewed: from flow injection to bead injection. Anal Chem 71: 257A-263A.

SANTOS JR AND RANGEL AOSS. 2012. Development of a chromatographic low pressure flow injection system: Application to the analysis of methylxanthines in coffee. Anal Chim Acta 715: 57-63.

SARTINI RP AND OLIVEIRA C. 2002. A new strategy for exploiting ion exchange in sequential injection analysis: In-line phytic acid separation/determination in foods as an example. Anal Sci 18: 675-679. 
SCHONBERG JN, BRANDSTETTER T AND RUHE J. 2015. Particle extraction in plug-based microfluidics. Procedia Engineer 120: 96-99.

SERRANO M, BARTOLOMÉ M, BRAVO JC, PANIAGUA G, GAÑAN J, GALLEGO-PICÓ A AND GARCINUÑO RM. 2017. On-line flow injection molecularly imprinted solid phase extraction for the preconcentration and determination of 1-hydroxypyrene in urine samples. Talanta 166: 375-382.

SHISHOV A, ZABRODIN A, MOSKVIN L, ANDRUCH V AND BULATOV A. 2016. Interfacial reaction using particle-immobilized reagents in a fluidized reactor. Determination of glycerol in biodiesel. Anal Chim Acta 914: 75-80.

SILVA MM, ARRUDA MAZ, KRUG FJ, OLIVEIRA PV, QUEIROZ ZF, GALLEGO M AND VALCÁRCEL M. 1998. On-line separation and preconcentration of cadmium, lead and nickel in a fullerene (C60) minicolumn coupled to flow injection tungsten coil atomic absorption spectrometry. Anal Chim Acta 368: 255-263.

SILVESTRE CIC, PINTO PCAG, SEGUNDO MA, SARAIVA MLMFS AND LIMA JLFC. 2011. Enzyme based assays in a sequential injection format: A review. Anal Chim Acta 689: 160-177.

SKEGGS LT. 1957. An automatic method for colorimetric analysis. Am J Clin Pathol 28: 311-322.

STEWART KK, BEECHER GR AND HARE PE. 1976. Rapid analysis of discrete samples: The use of nonsegmented, continuous flow. Anal Biochem 70: 167-173.

TEIXEIRA LSG, LEMOS VA, COELHO LM AND ROCHA FRP. 2016. Applications of biosorbents in atomic spectrometry. Appl Spectrosc Rev 51: 36-72.

VAKH C, KORONKIEWICZ S, KALINOWSKI S, MOSKVIN L AND BULATOV A. 2017. An automatic chemiluminescence method based on the multi-pumping flow system coupled with the fluidized reactor and directinjection detector: Determination of uric acid in saliva samples. Talanta 167: 725-732.

VAN GEMERT JT. 1973. Automated wet chemical analysers and their applications. Talanta 20: 1045-1075.

VERPOORTE E. 2003. Focus Beads and chips: new recipes for analysis. Lab on a Chip 3: 60N-68N.
VIDA ACF, COCOVI-SOLBERG DJ, ZAGATTO EAG AND MIRÓ M. 2016. Rapid estimation of readily leachable triazine residues in soils using automatic kinetic bioaccessibility assays followed by on-line sorptive cleanup as a front-end to liquid chromatography. Talanta 156: 71-78.

VIDIGAL SSMP, TÓTH IV AND RANGEL AOSS. 2012. Determination of total protein content in white wines by solid phase spectrometry in a SI-LOV system. Talanta 96: 102-106.

VIDIGAL SSMP, TÓTH IV AND RANGEL AOSS. 2013. Sequential injection lab-on-valve platform as a miniaturisation tool for solid phase extraction. Anal Methods 5: 585-597.

WANG J AND HANSEN EH. 2001. Coupling sequential injection on-line preconcentration by means of a renewable microcolumn with ion-exchange beads with detection by electrothermal atomic absorption spectrometry. Anal Chim Acta 435: 331-342.

WANG L, HANG X, CHEN Y, WANG Y AND FENG X. 2016. Determination of cadmium by magnetic multiwalled carbon nanotube flow injection preconcentration and graphite furnace atomic absorption spectrometry. Anal Lett 49: 818-830.

XIONG Y, ZHOU H, ZHANG Z, HE D AND HE C. 2007. Flow-injection chemiluminescence sensor for determination of isoniazid in urine sample based on molecularly imprinted polymer. Spectrochim Acta A 66: 341-346.

YANG R, PAGADUAN JV, YU M AND WOOLLEY AT. 2015. On chip preconcentration and fluorescence labeling of model proteins by use of monolithic columns: device fabrication, optimization, and automation. Anal Bioanal Chem 407: 737-747.

YOSHIMURA K. 1987. Implementation of ion-exchanged absorptiometric detection in flow analysis systems. Anal Chem 59: 2922-2924.

ZAGATTO EAG, BRIENZA SMB, ARRUDA MAZ AND JACINTHO AO. 1993. Flow injection systems involving ion-exchange: basic configurations. Quim Nova 16: 130132. 